
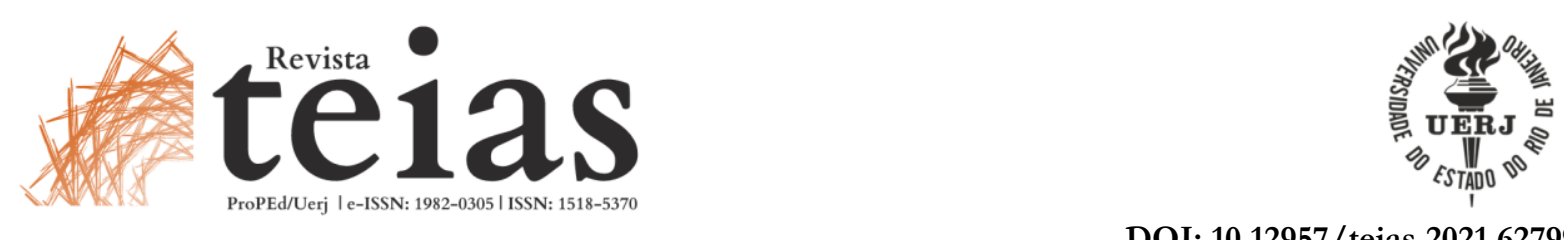

DOI: $10.12957 /$ teias.2021.62799

\title{
LAS TECNOLOGÍAS DIGITALES EN LA ESCUELA: antes y después de la pandemia de Covid-19
}

\author{
Judith Kalman ${ }^{1}$
}

\section{Resumen}

La pandemia Covid-19 vino a poner en evidencia las grandes desigualdades en los sistemas educativos y las experiencias escolares. Por un lado, desnudó las diferencias materiales en equipos, condiciones de estudio, conectividad y posibilidades de participación y por otro la pobreza en el uso de las tecnologías como un recurso pedagógico y un mediador de la enseñanza. Desde hace mucho, la política educativa en México, como en muchas otras partes del mundo, exige a los maestros que usen cada vez más diversas tecnologías digitales en sus aulas. Nunca como ahora con el traslado de las clases a la casa se ha visto cómo el incorporar estas tecnologías a la enseñanza es un proceso complejo que abarca la redefinición de las relaciones en el aula, la reinterpretación del currículo y la expansión de la noción de alfabetización académica más allá de los textos escritos. Este trabajo analiza cómo los maestros usan las tecnologías para responder y las aproveche para introducir formas novedosas para enseñar y aprender. Revisa datos recopilados antes de la pandemia para examinar los procesos de apropiación de las tecnologías para la enseñanza, y cómo aprenden en la práctica. Encontramos que aprender a utilizar las tecnologías digitales en actividades educativas implica continuas aproximaciones a través de su uso para poder pensar en ellas como un entorno de aprendizaje y reformular prácticas establecidas.

Palabras clave: Covid-19, tecnologías digitales, apropiación, práctica docente, aprender.

\section{Resumo}

A pandemia da Covid-19 pôs em evidência as grandes desigualdades nos sistemas educativos e nas experiências escolares. De um lado, desnudou diferenças materiais de equipes, de condições de estudo, de conectividade e possibilidades de participação e, de outro, a pobreza no uso de tecnologias como recurso pedagógico e mediador de ensino. Faz muito tempo, a política educativa no México, como em muitas outras partes do mundo, exige dos professores que usem cada vez mais diversas tecnologias digitais em suas turmas. Nunca, como agora, com a mudança das salas de aula para a casa se havia pensado como a incorporação dessas tecnologias ao ensino era um processo complexo que abarca a redefinição das relações na sala de aula, a reinterpretação do currículo e a expansão da noção de alfabetização acadêmica para além dos textos escritos. $\mathrm{O}$ artigo analisa como professores usam as tecnologias para responder e como as aproveitam para introduzir formas inovadoras de ensinar e de aprender. Faz a revisão de dados coletados antes da pandemia para examinar processos de apropriação das tecnologias para o ensino, e como aprendem na prática. Percebe-se que aprender a utilizar tecnologias digitais em atividades educativas implica contínuas aproximações pelo uso para poder pensá-las como ambiente de aprendizagem e reformular práticas estabelecidas.

Palavras-chave: Covid-19; tecnologias digitais; apropriação; prática docente, aprender.

\section{Abstract}

The Covid-19 pandemic shed light on the significant inequalities in education systems and school experiences around the world. On the one hand, it exposed the material differences in equipment, study conditions, connectivity, and participation possibilities and, on the other, the limited nature of the use of technologies as a pedagogical resource. As in many other parts of the world, education policy in Mexico has long required teachers to use diverse digital technologies in their classrooms. Never like now, with the transfer of classes to home

\footnotetext{
${ }^{1}$ Agradezco a Patricia Valdivia por su ayuda en la preparación de este manuscrito.
} 
environments, has the complexities of incorporating these technologies been so evident. Doing so requires a redefinition of relationships among participants, a reinterpretation of the curriculum, and an expansion of the notion of literacy academic beyond written texts. This paper reviews data collected before the pandemic to examine the processes of appropriation of technologies for teaching and how they learn in practice. We found that learning to use digital technologies in educational activities implies continuous development of approaches to be able to conceptualize the computer and Internet as a learning environment and reformulate established practices.

Keywords: Covid-19; digital technologies; appropriation; teaching practice; learning.

\section{INTRODUCCIÓN}

La pandemia Covid-19 vino a poner en evidencia las grandes desigualdades en los sistemas educativos y las experiencias escolares. Por un lado, desnudó las diferencias materiales en equipos, condiciones de estudio, conectividad y posibilidades de participación y por otro la pobreza en el uso de las tecnologías como un recurso pedagógico y un mediador de la enseñanza. Desde hace mucho, la política educativa en México, como en muchas otras partes del mundo, exige a los maestros que usen cada vez más diversas tecnologías digitales en sus aulas. Nunca como ahora con el traslado de las clases a la casa se ha visto cómo el incorporar estas tecnologías a la enseñanza es un proceso complejo que abarca la redefinición de las relaciones en el aula, la reinterpretación del currículo y la expansión de la noción de alfabetización académica más allá de los textos escritos. Para que los maestros usen las tecnologías para responder a la situación actual y las aproveche para introducir formas novedosas para enseñar y aprender, es necesario tomar riesgos y construir nuevos parámetros acerca de qué es el trabajo académico, la interacción en el aula, el currículo y la evaluación. Aquí se parte de la idea de que la docencia se construye con "racimos de prácticas" (SCHATZKI, 2010), es decir, con la articulación de múltiples acciones, objetos, tradiciones, condiciones, conocimientos, normas y usos de lenguaje.

Mucho antes de la pandemia, los investigadores educativos mostraron diversos datos que, por un lado, registraron la presencia de diversos dispositivos y la conectividad en las escuelas, pero por otro, lo poco que los profesores las usaban (CUBAN, 2000; JARA-VALDIVIDA, 2008; McFARLANE, 2001). Algunas explicaciones comunes de esta situación son que los maestros no usan la tecnología en su trabajo docente porque no han recibido la capacitación para hacerlo, que sus escuelas no proporcionan el software especializado necesario para sus asignaturas académicas, o porque sienten que no están lo suficientemente familiarizados con la tecnología digital para enseñar a los jóvenes cómo usarla cuando sus estudiantes probablemente ya lo saben.

La llegada de las computadoras (portátiles y de escritorio), la conexión a internet, los proyectores y los dispositivos móviles en las aulas de México tienen una historia particular que nos ayuda a comprender cómo y por qué los maestros usan estas tecnologías de cierta manera, es decir, por qué hacen lo que hacen (GEERTZ, 1983). Promovidas desde finales de los años noventa por las agencias internacionales y los encargados de formular políticas nacionales como el nuevo "deber ser" educativo, los dispositivos y el internet se impulsaron como el motor del crecimiento económico y la prosperidad; su introducción a la educación formal constituyó una parte de las estrategias para el desarrollo. Ahora durante los periodos de confinamiento obligado por la pandemia, el uso de las tecnologías se ha vuelto sinónimo con la posibilidad de continuar, aunque sea de manera remota, con las clases en los programas de educación formal, el trabajo de distintas organizaciones y empresas, la provisión de servicios, las consultas médicas, y los trámites. Es decir, ante el peligro del contagio, los 
entornos digitales sincrónicos y asincrónicos se han convertido en un mediador indispensable para muchas de las actividades que antes realizábamos de forma presencial.

Sin embargo, a pesar de las inversiones en equipos y en dispositivos digitales antes de la crisis sanitaria de 2020, se ha pensado poco en qué hacer con ellos una vez que están allí. Parecería que las autoridades no entendían de qué se trataba lo digital y se invertía pocos recursos en la formación docente, por ejemplo, Guerrero (2011) informó que la Secretaría de Educación Pública (SEP) gastó menos de quinientos pesos por maestro en desarrollo profesional en todas las áreas académicas. La premisa parece ser que los maestros harían una transición natural para usar estos artefactos. Lo que hemos visto es que un número importante de los profesores, durante la pandemia y mucho antes, se preguntan qué hacer con las computadoras de escritorio, las computadoras portátiles y las tabletas que se les proporcionaron. Una de las opciones que se ha documentado es usarlos para explicar conceptos a sus estudiantes y reemplazar el pizarrón con coloridas presentaciones de PowerPoint (GUERRERO, 2011). Otro es buscar ejercicios y otros materiales educativos en internet y mostrarlos a los estudiantes, pidiéndoles que trabajen individualmente o en pares para completar tareas específicas en una pantalla (GUERRERO, 2011). Durante estos meses de educación remota urgente, la conexión a internet ha sido clave para mantener el contacto con los estudiantes, dar continuidad a la escuela de alguna manera, distribuir materiales y ejercicios y recibir tareas de los alumnos. Menos comunes son aquellos profesores que se apropian de prácticas digitales para la creación de situaciones colaborativas, el diseño de textos y despliegues multimodales originales, la participación en distintos tipos de redes, y el aprendizaje independiente, características de lo que se ha denominado "cultura digital" (LANKSHEAR, KNOBEL, 2007; 2011).

Para muchos maestros, esto a menudo implica aprender a operar la computadora, pero esto es solo una parte de lo que necesitan aprender. Lankshear y Knobel (2011) distinguen entre los docentes que ven en el uso de la tecnología el "dominio de las ideas" y otros que se ocupan más de sus aspectos técnicos. La distinción entre un enfoque en el pensamiento analítico y otro en las habilidades técnicas es importante. Nuestra preferencia es la primera, centrada en el dominio de las ideas y los procesos analíticos, a lo que también añadimos que la enseñanza con tecnología implica redefinir las relaciones en el aula, reinterpretar el currículo y ampliar la noción de alfabetización académica más allá de los textos escritos.

Aquí se presenta la participación de dos maestras que asistieron en 2012 a talleres del Laboratorio de Educación, Tecnología y Sociedad (LETS) del Departamento de Investigaciones Educativas del Centro de Investigación y Estudios Avanzados del IPN en México. Aunque los datos provienen de un tiempo previo a la situación actual que vivimos, ilustran con claridad los procesos de incorporación de algunos usos de las tecnologías digitales a las actividades escolares. Las dos maestras son jóvenes, con cierto conocimiento de las tecnologías, pero su comprensión y sus soluciones pedagógicas hacen un contraste interesante e iluminan las complejidades del proceso de apropiación. 

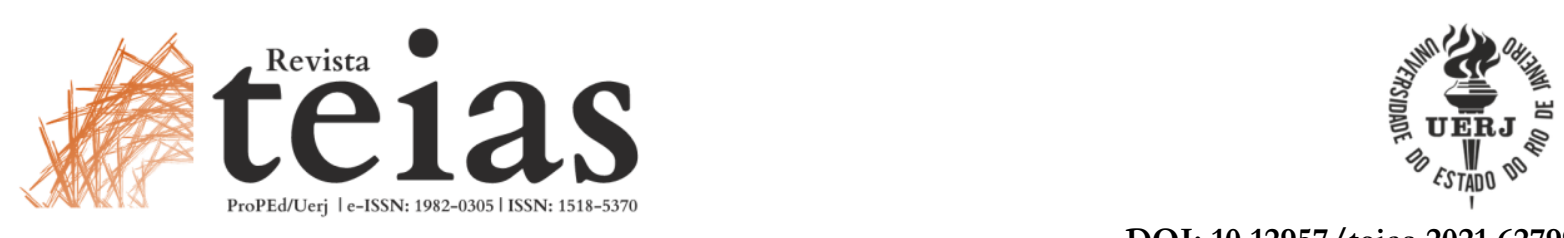

DOI: $10.12957 /$ teias.2021.62799

\section{TECNOLOGÍAS DIGITALES Y FORMACIÓN DOCENTE}

Como parte del proyecto de investigación Los profesores y las TIC: La apropiación del conocimiento en la práctica (2012-2015) el LETS ofreció un taller a profesores de educación secundaria cuyo enfoque de trabajo consistió en establecer propuestas desafiantes para promover el aprendizaje y usar las tecnologías digitales de manera efectiva en sus contextos de enseñanza, pero lo suficientemente familiares como para que se sintieran cómodos tratando de hacerlo. Por lo tanto, nuestra función fue brindar asistencia guiada (ROGOFF, 2008) a través del diseño de situaciones que enfrentaron en una relación de colaboración, en lugar de una relación experto-novato. Nuestro objetivo fue contribuir a su comprensión de las prácticas digitales a través de la participación con sus colegas y con los alumnos.

En México, las prácticas de enseñanza dominantes están impregnadas de una pedagogía tradicional que tiene sus raíces históricas en una visión de aprendizaje centrada en la acumulación de información. Desde esta perspectiva, la enseñanza requiere un control estricto de los procedimientos, contenidos y secuencias derivadas de la fragmentación del contenido, la desintegración del conocimiento y la evaluación del aprendizaje. A pesar de las críticas recibidas y el desfase en las condiciones históricas que vivimos en la actualidad, el modelo conductista ha proporcionado un marco conceptual para la escolarización en esta tradición, conceptualizando el aprendizaje como la adquisición de conocimientos mediante la repetición mecánica y la recepción pasiva (ROGOFF et al., 2003).

En cambio, las pedagogías transformativas están basadas en nociones dinámicas de los conceptos de aprendizaje, conocimiento, vida social y relaciones entre los participantes. Aquí enfatizamos el aspecto activo y destacamos la gran cantidad de acciones que ser realizan para aprender, conocer y relacionarse. La noción subyacente de aprendizaje es socio-constructivista, por lo que el aprendiz es un participante protagónico en el desarrollo, apropiación y estructuración del conocimiento, y enfatiza la importancia de la interacción con los demás, la mediación por artefactos culturales, la contextualización, la historicidad y las relaciones sociales como parte del aprendizaje: no solo importa lo que se aprende sino con quién, para qué y en qué contexto (HERNÁNDEZ, 2013). Aquí, la actividad principal de los profesores se centra en diseñar situaciones en las que los estudiantes interactúen, intercambien puntos de vista, experimenten con ideas nuevas y participen en actividades culturalmente valoradas. Esto implica que los profesores posibiliten contextos donde las responsabilidades, la autoridad y el conocimiento sean compartidos.

En el inicio del proyecto de investigación, planteamos a las tecnologías de información comunicación y diseño (TIC-D) como entornos y herramientas que extienden la producción de significados culturales y sociales generados históricamente a través del uso de la lengua escrita. Por un lado, su uso podría potencialmente transformar prácticas comunicativas cotidianas, ya que son herramientas poderosas que integran múltiples recursos para la expresión y la representación de significados y conocimientos; ofrecen conectividad, y con ella, comunicación instantánea; aumentan el

\footnotetext{
${ }^{2}$ Los integrantes del equipo de LETS para este proyecto fueron Víctor Rendón Cazales, Laura Macrina Gómez Espinoza, Tonatiuh Paz Aguilar, Wendy Yuridia Piza Cortés, Elsa Guerrero Salinas. Este artículo se basa en el informe final de este proyecto. Se puede conocer una versión extensa https: $/ /$ www.crefal.org/index.php?option $=$ com content\&view $=$ article\&id $=560 \& I$ temid $=202$.
} 


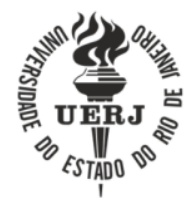

DOI: $10.12957 /$ teias.2021.62799

potencial de almacenaje de información y datos; y brindan opciones de entretenimiento y de experiencias estéticas. Por otro lado, su uso y diseminación generan nuevas prácticas comunicativas de lectura y escritura (LANKSHEAR, KNOBEL, 2007), de representación (KRESS, 2003), de interacción (KNOBEL, LANKSHEAR, 2011) y nuevas formas de conocimiento (LEANDER, 2007; NELSON, 2006).

Para transitar hacia la incorporación de las tecnologías digitales a la educación formal (KALMAN, 2004), el acceso a prácticas que las involucren depende de la inclusión o exclusión de estas nuevas formas de interactuar, conocer y comunicarse. La investigación educativa no puede ignorar la diseminación social de las TIC-D y su impacto en la vida comunicativa de la sociedad. Para los profesores, esto implica comprender y manejar las formas de representación que son cada vez más significativas en los contextos comunicativos, el uso de recursos gráficos y su relación con textos escritos, el diseño de publicaciones locales y las opciones de comunicación sincrónica y asincrónica (NEW LONDON GROUP - NLG, 1996).

Una de las premisas de la inserción de la tecnología al ámbito escolar, es que mejorará el aprendizaje de los alumnos. Por ejemplo, Álvaro Marchesi (2009, p. 7), presidente de la OEI señaló en 2009 que:

La tarea principal $[\ldots]$ es lograr que los alumnos mejoren sus aprendizajes con la utilización de las tecnologías de la información. Pero ello supone configurar un nuevo escenario en las relaciones entre los profesores, los alumnos y los contenidos de la enseñanza, y hacerlo también en la evaluación de todo el proceso de enseñanza y de aprendizaje.

De esta manera Marchesi promueve la idea de que el mejoramiento de los aprendizajes también requiere nuevas formas de enseñanza, así como prácticas docentes alejadas de acciones que privilegian la transmisión y la repetición de contenidos académicos fragmentados, en un contexto de relaciones jerárquicas controladas por el docente y centradas en él (COOK-GUMPERZ, 1986; DAVIDSON, 2011; HERNÁNDEZ, RENDÓN, KALMAN, 2016; LUKE, 2000; ROGOFF et al., 2003). Marchesi (2009, p. 7) propone que la formación de los profesores debe permitir que se "[...] incorporen las TIC de manera natural", sin embargo, la literatura internacional ha revelado, una y otra vez, que el desplazamiento hacia pedagogías transformativas no es natural. En la mayoría de los casos, las didácticas que promueven la idea de un aprendiz activo en el desarrollo, apropiación y organización del conocimiento, requieren de una profunda reconceptualización del aprendizaje, del quehacer docente y del sentido de la escuela (COPE, KALANTZIS, 2000; KNOBEL, LANKSHEAR, 2014; WARSCHAUER, 2002).

La teoría socio-constructivista resalta la importancia de la interacción con otros como una parte inherente al aprender. Desde esta perspectiva, el papel central del maestro no es supervisar ejercicios, cuestionarios o lecturas en voz alta, más bien se trata de diseñar situaciones en las cuales los alumnos interactúen, intercambien nuevos puntos de vista, experimenten con nuevas ideas y metodologías y participen en actividades sociales y culturales valoradas en un ámbito donde se comparte la responsabilidad, la autoridad y el conocimiento. La contextualización del contenido curricular en el mundo del alumno y de alguna manera desde su experiencia, es clave para comprender conceptos, establecer relaciones y articular ideas; de hecho, Simon (1992), considera que es uno de los aspectos más importantes de lo que se estudia y se aprende. 


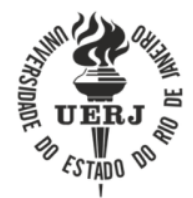

DOI: $10.12957 /$ teias.2021.62799

Soltar cuando menos una parte del control históricamente asignado al maestro es un desplazamiento fundamental que suele ser muy difícil para muchos docentes (DREIER, 1999; LAVE, 2011; SUTHERLAND, ROBERTSON, JOHN, 2009). Sin embargo, cuando lo logran se dan cuenta que la nueva distribución de la autoridad y responsabilidad crea oportunidades para renovar las actividades en el aula de maneras antes insospechadas (KALMAN, GUERRERO, 2013; KALMAN, RENDÓN, 2014). Sostenemos que para que los maestros logren la transición de prácticas docentes tradicionales a prácticas transformadoras, deben entender las características y las conceptualizaciones que sostienen las propuestas pedagógicas nuevas y comprender el alcance de los usos potenciales de la representación multimodal, de la conectividad y de los ambientes digitales, a partir de sus propiedades posibilitadoras (affordances) y los planos de análisis del uso de las TIC-D que expresan las posibilidades que brindan las tecnologías en situaciones educativas específicas (McFARLANE, 2001; SUTHERLAND et al., 2004).

Establecido lo anterior, iniciamos nuestro estudio y nuestro trabajo con los profesores suponiendo que:

- Los profesores necesitan construir conocimientos acerca de los affordances que ofrecen las tecnologías digitales y la conectividad como entornos sociales y como herramientas integradoras poderosas, para articularlos con el conocimiento disciplinario de su asignatura y su forma de enseñar. Este proceso puede provocar transformaciones en el diseño de situaciones de aprendizaje, en las formas de interacción en el aula y en la evaluación de sus alumnos.

- Es necesario construir una transición de las pedagogías "tradicionales" a las "transformativas" para incorporar el uso de las TIC en la práctica docente (BIGUM et al., 1997; CUBAN, 2000; McFARLANE, 2001).

- La presencia de otros y la colaboración son claves para la construcción de estos conocimientos y prácticas.

Sin embargo, la experiencia de este proyecto mostró que acercarse a las dimensiones conceptuales, a las nuevas prácticas digitales, a los procedimientos técnicos relacionados con tales prácticas, a las herramientas específicas y a distintos modos de representación es una parte medular de lo que un profesor necesita conocer y saber hacer, pero que este conocimiento no basta para que un profesor transforme su práctica e incorpore las tecnologías al aula. El trabajo con los profesores nos obligó a profundizar nuestra construcción de lo que los maestros tendrían que conocer, cómo llegarían a conocerlo y para qué. Esto nos llevó a enfocarnos en el análisis de la dimensión epistemológica del problema y a la conceptualización del aprendizaje que revele lo que implica la transformación en la forma de relacionarse con los alumnos, con el conocimiento y con el trabajo. En pocas palabras, nos interesó indagar lo que sabían los maestros y cómo llegaron a saberlo (Hernández, 2013).

Durante las sesiones de trabajo tratamos de construir, en conjunto con los profesores, formas de reflexionar, imaginar y diseñar situaciones didácticas con el uso de prácticas digitales, de tal manera que en este proceso se atendiera a las características, necesidades y problemáticas específicas de los docentes. Partimos de una conceptualización de práctica social basada en Scribner y Cole (1981, p. 236), quienes entienden la práctica como "[...] maneras de uso de tecnologías y conocimientos para realizar tareas reiteradas, regulares y socialmente desarrolladas". A esta conceptualización Barton y Hamilton (1998) agregaron la noción de las dimensiones invisibles de las prácticas sociales (las ideas, las creencias y las valoraciones) como factores presentes en las formas de participar en eventos 

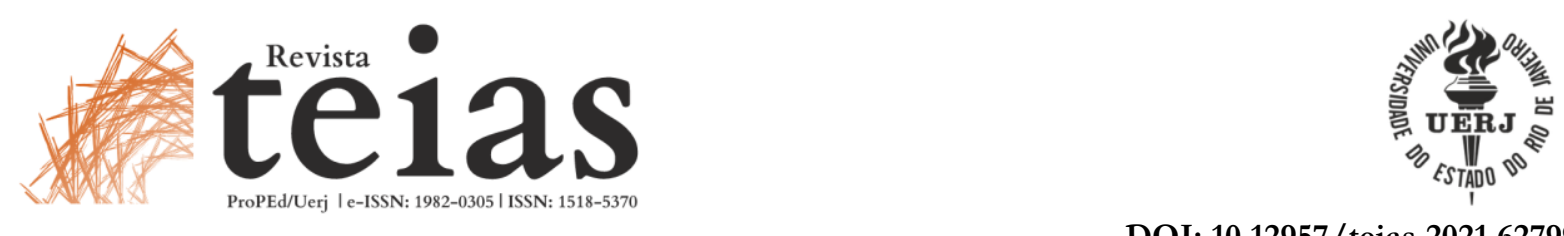

DOI: $10.12957 /$ teias.2021.62799

específicos. Pusimos atención especial a las condiciones de trabajo, las materialidades, el repertorio didáctico y los recursos semióticos de los profesores participantes.

En este proceso forjamos una metodología de trabajo a partir de la noción de acompañamiento, que fue construida alrededor de cinco aspectos interrelacionados.

El primero de ellos es la continuidad de las acciones desarrolladas entre: los maestros participantes y el LETS; entre los docentes con sus pares; y entre los maestros con sus estudiantes. De esta forma se construyeron actividades interrelacionadas y se promovió la comunicación permanente entre los participantes.

La colaboración es un segundo aspecto clave que se entiende aquí como un compromiso en la realización de las actividades (LAVE, WENGER, 1991), a través del apoyo mutuo en donde la participación guiada y la apropiación participativa (ROGOFF, 2008) son procesos inseparables en la construcción de los diferentes usos de las tecnologías digitales para el aula.

El tercero se refirió a la realización de prácticas colectivas de reflexión fundamentadas en el diálogo, lo cual implicó momentos en donde se pusieron sobre la mesa las palabras propias empleadas en la discusión de la experiencia docente para resaltar expectativas, ideas y creencias.

El cuarto aspecto fue la construcción colectiva, referida a la imaginación de posibles actividades, productos culturales y procesos relacionados con la enseñanza con entornos digitales.

Finalmente, se promovió el desarrollo de una mirada analítica de los maestros sobre su propio trabajo, a través de la documentación de las actividades con tecnologías que diseñaban y llevaban a cabo en el aula.

A continuación, se examina cómo dos profesoras incorporaron la realización de un video en las actividades de la clase de español (lengua materna). A pesar de que las dos trabajaron a partir de la

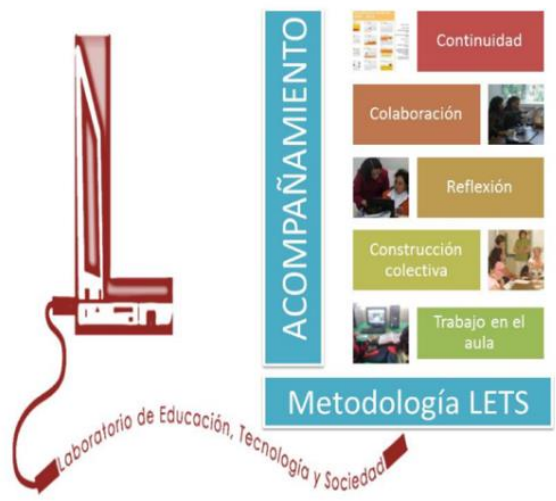
misma consigna, su conceptualización y la realización de la actividad fue muy diferente.

Caso 1: La maestra Hilda, el video y el examen

Siguiendo el programa de estudios de Español de Primer grado de secundaria, la maestra Hilda pidió a sus alumnos que retomaran un trabajo que hicieron para las materias de Biología o de Geografía (los alumnos podrían elegir con cuál trabajar) y lo convirtieran en un video. Inició esta actividad escribiendo una definición de monografía en el pizarrón y solicitó a los alumnos que consultaran en sus libros de texto información al respecto, lo comentaran o agregaran elementos.

Les pidió crear un video utilizando la herramienta Windows Movie Maker con cinco diapositivas basadas en las ideas principales de su trabajo escrito.

Hilda contempló cinco sesiones de clase más la realización de tareas en casa para el desarrollo de esta actividad, en una de ellas contó con la asistencia de la profesora de aula de medios de su escuela, quien la apoyó en la explicación de asuntos técnicos al trabajar con imágenes. El resto de las sesiones corrieron a cargo de la maestra Hilda quien inició explicando qué es una monografía, luego abordó 
cuestiones formales del trabajo (ajuste de imágenes y texto de las diapositivas), en seguida trabajó con la selección y manejo de la información, y por último trabajaron la producción del video.

La propuesta de trabajo de la profesora ilustra los elementos que considera importantes en la elaboración de este producto: el número de diapositivas, el formato de las imágenes, el resumen de la información, el uso de bibliografía y la inclusión de imágenes y sonidos. Estas monografías surgieron a partir de la idea de trabajar con un producto previamente elaborado por sus alumnos en Biología o Geografía sobre diversos temas como obesidad, placas tectónicas o noviazgo. Las monografías realizadas en video contenían diversos elementos como mapas con la localización de las placas tectónicas del mundo, gráficas con información estadística, recomendaciones, definiciones, así como la inclusión de las fuentes de información, por mencionar algunos.

Esta actividad fue evaluada a través de un examen escrito que buscaba validar conocimientos de sus alumnos sobre cómo se elabora una monografía en papel y una en computadora, haciendo énfasis en el formato utilizado: un video.

15052 Hilda: el día de antier le hice examen al $1^{\circ} \mathrm{A}$

$[\ldots]$

15062 entonces en la pregunta 9 les dije ¿cuáles son los pasos para elaborar una monografía escrita que vayas a entregar impresa?

15063 les digo pongan atención porque la 10 es ¿cómo elaborar una monografía en video?

15064 (Un alumno preguntó durante el examen) ¿y quiere los pasos detalladamente como guardar cómo?

15065 le digo no exactamente pero sí la guardé en tal formato

15066 la guardé en tal memoria o de esta manera

15067 ah sí

15068 eso fue en $1^{\circ} \mathrm{A}$

15069 Hilda: el día de ayer hice en $1^{\circ} \mathrm{B}$ les digo la misma pregunta

15070 digo ¿cómo hacer una monografía escrita o impresa? Y ¿cómo van a hacer una monografía en video? ¿cuáles son los pasos?

15071 (Reporta el comentario de un alumno) pero no hicimos monografía

15072 eso no lo vimos

15073 le digo ah ¿no lo vimos?

15074 hicimos un video, pero no hicimos monografía

15075 le digo ah entonces ahí ya nos perdimos

15076 y sí se me hizo así como en el $1^{\circ}$ A no me dijeron nada sobre eso

15077 y en el $1^{\circ} \mathrm{B}$ así como que -

15078 digo entonces la maestra de español se los llevó a pachanguear a hacer videos a red

Fuente: RS 3

La maestra comentó que algunas preguntas planteadas en el examen apelan a los pasos para elaborar una monografía (15062) lo que sugiere que, para Hilda, la realización de un trabajo como éste es equivalente a transitar por una serie de pasos técnicos que los alumnos deben poder declarar de manera correcta, especificando qué hicieron y cómo lo hicieron, por lo que enfoca su atención en el procedimiento técnico más que en el proceso de elaboración de las producciones realizadas o los 
conocimientos construidos sobre la marcha. Asimismo, la evaluación de lo que los alumnos saben hacer para crear un producto digital se reduce a la escritura de esos pasos.

En la configuración de esta actividad, Hilda asocia la operación de la herramienta Movie Maker y el conocimiento de los formatos que el programa permite manipular con la capacidad de describirlos por escrito en un examen (15063). Lo que parece tener un peso particular aquí es la equivalencia de la evidencia del aprendizaje con el conocimiento declarativo de los contenidos y los procedimientos, así como la tradición didáctica e institucional de calificar (más que evaluar) los aprendizajes mediante una prueba escrita. Hilda expresa en diferentes momentos esta preocupación por cumplir con las líneas institucionales de manera estricta. Por ejemplo, en un cuestionario sobre las actividades realizadas durante el mes de octubre, reportó que sus alumnos "[...] realizaron un mapa mental sobre mitos y leyendas y un cuadro de diferencias entre cada uno" y señaló "Me preocupa que mi tema no coincide con la búsqueda de información, sino que se refiere a la representación de información”. Es posible apreciar que le inquietaba que no estaba cumpliendo cabalmente con el mandato del currículo que estipula que los alumnos deben buscar información, pero no menciona que la deben representar.

Hilda realizó el mismo examen con varios grupos y encontró una situación inesperada con uno de ellos, pues sus alumnos no entendieron que el video que realizaron correspondía a un formato visual de la monografía que hicieron para la otra asignatura. En su narración, refiere que algunos de sus alumnos no identificaron que trabajaron el género de la monografía, pero sí recordaban haber realizado un video. Hilda se mostró desconcertada cuando mencionó que "se perdieron" en el tema, y menciona de forma irónica lo que asume que un grupo de sus alumnos percibió: "[...] la maestra de español se los llevó a pachanguear" (15075-15078).

Este fragmento dibuja nuevamente la preocupación y el compromiso de Hilda con la institución escolar mediante una interpretación del programa de estudio como un temario que se debe seguir al pie de la letra y su preocupación por cubrirlo a cabalidad. De manera similar, recalca la prevalencia del conocimiento declarativo acerca de los procedimientos sobre los contenidos. Es decir, solicitó a sus alumnos que repitieran los pasos que siguieron, pero no les solicitó ningún tipo de reflexión o construcción propia acerca del contenido de sus trabajos o las decisiones que tomaron para realizarlo (15063 a 15065). En este examen, el procedimiento para elaborar la monografía resultó de mayor importancia frente a los elementos contenidos en los propios trabajos como las formas de representación, la temática, la organización del contenido o las maneras de citar la información e incluso la definición de una monografía. El ejemplo anterior muestra, por lo menos en parte, algunas de las ideas que Hilda tiene al trabajar con tecnología:

- Es secundaria a la escritura.

- Consiste en una serie de pasos técnicos como guardar información, realizar diapositivas o bajar imágenes.

- Las acciones que sobresalen del manejo de la información son investigar, resumir, sacar ideas principales.

- Los pasos a seguir para realizar un objeto cultural (en este caso el video) se traducen a un contenido que el alumno debe ser capaz de declarar y repetir.

Esto sugiere que la visión de Hilda de "investigar" y "usar la tecnología” es más bien un asunto de procedimientos, y apunta que recorrer los pasos conduce a la realización de un buen trabajo. Insinúa que la maestra se enfoca en el producto terminado y sólo considera importante el camino técnico para llegar a su elaboración sin considerar otros aspectos de la construcción del conocimiento, como la 

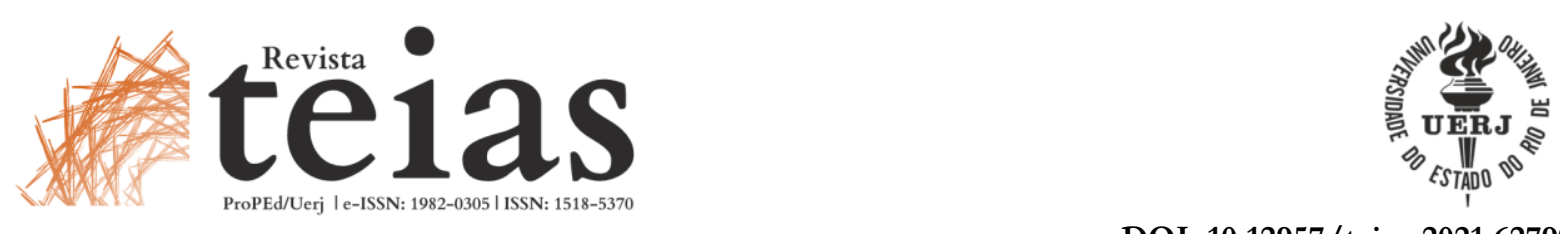

DOI: $10.12957 /$ teias.2021.62799

exploración de ideas, las conexiones entre conceptos y datos, la relación entre la experiencia y el aprendizaje o la toma de decisiones en el proceso de elaboración. Parece que busca verificar los pasos que ella supone necesarios para elaborar una monografía en video y que asume que los alumnos los transitaron para realizar su trabajo. Privilegia la definición del procedimiento e invisibiliza lo que los estudiantes hicieron (y experimentaron) al enfrentar la realización del video y los elementos contenidos en los propios trabajos.

Este ejemplo ilustra también cómo la maestra Hilda articula sus nociones didácticas, el contenido curricular de su materia, el uso de la computadora e internet y las sugerencias de LETS mediante ciertas vinculaciones, algunas más fuertes e intensas que otras. De hecho, la actividad ("hacer un vídeo") resultante es un "racimo de prácticas" provenientes de diversos espacios y tiempos, orígenes y entendimientos (SCHATZKI, 2010): la elaboración inicial de la monografía arraigada en el currículo, el uso de la tecnología para elaborar un producto cultural sugerido en el taller, el examen como instrumento de evaluación propuesto desde la didáctica tradicional, entre otros. Su conexión con la institución escolar (mediante su interpretación del programa de estudio) junto con su construcción de la tarea docente como administrador de los contenidos y temáticas, es un lazo robusto y sólido, cimentado en su asociación con una didáctica transmisora. Sin embargo, también tienen presencia otras conexiones - con lo que los alumnos hacen y preguntan, con los affordances de la tecnología y con su relación naciente con LETS - que se expresan también en su narrativa de los eventos.

\section{Caso 2: La maestra Lucía: "La clase al revés"}

Observamos con frecuencia en los profesores participantes una forma común y estable de imaginar y planear las actividades para el aula. La mayoría de los profesores participantes comentaban una forma estereotipada de realizar las actividades, una especie de "molde" que todos seguían en mayor o menor medida: a) dar el tema, generalmente una exposición por parte del docente sobre definiciones de los contenidos curriculares que se abordaran; b) realización de un trabajo (la mayoría de las veces ejercicios) por parte de los alumnos, en el cual se buscaba y seleccionaba información, misma que se remitía a aspectos factuales, los cuales frecuentemente eran copiados y pegados de un lugar a otro; c) exposición de los productos, donde se mostraba al resto del grupo lo que se había realizado, este paso en ocasiones incluía la retroalimentación sin oportunidad de mejorar los productos con estas recomendaciones. Cualquier intento de transformar la práctica requería que los profesores pudieran reconocer este molde como tal, comprender sus alcances y limitaciones, cuestionarlo y luego proponer y ensayar alternativas.

$\mathrm{Al}$ introducir las actividades complejas como el video en el salón de clases, los profesores tenían que participar con sus estudiantes y guiarlos en el proceso de producción. Varios profesores consideraban estas actividades como extras y otros expresaban que ocupaban mucho tiempo y demandaban mucha atención.

Para los profesores participantes en el taller, la idea de acompañar a los alumnos en el proceso de elaboración, hacer cortes antes de terminar para revisar, compartir y sugerir, resultó novedosa. Parafraseando a Rogoff (2008), aquí quisimos propiciar una forma de enseñanza en la cual el proceso es el producto, un proceso donde el profesor y los alumnos no esperan el producto final para reflexionar, profundizar y mejorar. Para ello introdujimos el concepto de productos intermedios, ensayamos distintas formas de detener y reflexionar sobre los avances y promovimos diferentes formas 


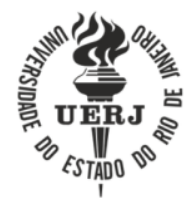

DOI: $10.12957 /$ teias.2021.62799

de retroalimentar a los estudiantes sobre el desarrollo de su trabajo. También buscamos opciones para involucrar a los mismos estudiantes en las decisiones sobre materiales, contenidos y representaciones y abrir las discusiones y reflexiones acerca de los trabajos al grupo escolar y a su profesor como una actividad y responsabilidad colectiva.

"La clase al revés", estuvo dirigida precisamente a intentar cambiar la forma de organizar y secuenciar la actividad en el aula. Como resultado, la realización del video de los alumnos de Lucía difiere en maneras sustanciales a la actividad realizada por los alumnos de Hilda. En la última sesión del taller, Lucía comentó la forma en que estaba realizando una actividad en el aula:

[Las actividades se hacen] con todas las cuestiones formales de la temática y todo ello lleva al producto, [los maestros] lo llevamos de la manita, tal como nosotros lo estamos visualizando y ahora empecé por el producto primero y después los chicos analizaban el proceso que llevaron a cabo para obtener ese producto que fue un reportaje, ya después ellos se enfrentaron al problema; tuvieron que buscar qué es un reportaje, sus características y demás que algunos no lo hicieron, porque ya al revisar los videos veíamos que faltaban muchas cosas. (RS 7)

La maestra inició su intervención con una diferenciación entre la clase más frecuente y la "clase al revés". En la primera, comentó que el docente es quien empieza a revisar los conceptos "con todas las cuestiones formales de la temática" dirigidas a la realización de una tarea, también definida por el profesor. Para la maestra, esta forma de trabajo es muy asistida por el docente ya que se "lleva de la manita" a los alumnos, además de estar planteada desde cómo lo ve el profesor mismo. En contraste, la "clase al revés" empezó con la producción primero (realizar un reportaje) y sobre la marcha analizaron el proceso involucrado en el desarrollo de la actividad y discutían diferentes conceptos necesarios para realizarla. En esta forma de organización, la maestra dejó que los alumnos se enfrentaran con "el problema" y tuvieron ellos mismos que buscar qué era un "reportaje, sus características y demás".

La maestra comentó que algunos alumnos no hicieron esta búsqueda y esto se evidenciaba en la revisión, no obstante, como el énfasis estuvo en el proceso más que en el producto, la revisión servía para señalar estos aspectos y mejorar los trabajos. La manera en que se trataron los contenidos curriculares en la "clase al revés" también tuvo algunas diferencias respecto a la organización más frecuente. En la siguiente cita, la maestra Lucía explicó cómo abordó el aspecto de contenido en este nuevo planteamiento:

Aquí la idea fue que partimos del contexto, de lo inmediato, de decir lo que era un reportaje y demás; digo, de todo momento, hay un canal, creo que en el 40 que los chicos todo el tiempo están viendo y demás, entonces socializamos así en lluvia de ideas lo que creemos que significa un reportaje, posteriormente ellos buscaron en diversas fuentes información sobre reportaje [...], posteriormente se hizo la lluvia de ideas y cada uno en plenaria se formó un concepto de qué es un reportaje, las características, pero los ejemplos los tomamos de los trabajos que ellos ya habían hecho, del producto; y eso es mejor a decir, "bueno, un reportaje es esto y esto". (RS 7)

En este apartado, Lucía comentó que el abordaje de los contenidos estuvo relacionado con el contexto inmediato de los estudiantes. Esto implicó hablar sobre ideas generales de lo que era un reportaje sin llegar a una definición formal, por ejemplo, con los reportajes que ven en la televisión,

Revista Teias v. $22 \bullet$ n. $67 \bullet$ out./dez. $2021 \bullet$ 
incluso con una lluvia de ideas. A partir de ahí inició la búsqueda de información sobre lo que era un reportaje a la par de la temática que abordaría cada equipo en su trabajo, temática que ellos mismos "habían elegido", enfatizando que nadie se las asignó.

El contenido conceptual de lo que era un reportaje se llevó a cabo de forma colectiva a partir de la "lluvia de ideas" en plenaria donde cada quién construyó el concepto de reportaje, sus características y de forma continua. En cada sesión se revisitaba el concepto y se extendía. Esta construcción conceptual se complementó con ejemplos que los mismos estudiantes habían elaborado. Ante esto, Lucía estableció un contraste con el "molde" de la clase donde se plantea que "un reportaje es esto y esto", haciendo referencia a la exposición conceptual por parte de la maestra, además de tomar ejemplos ajenos a los trabajos de los alumnos, ejemplos que pueden encontrarse en internet o algunos escritos.

\section{LAS PRÁCTICAS DE HILDA Y LUCÍA LADO A LADO}

Es posible mostrar la diferencia en la configuración de estas actividades de manera gráfica. La siguiente tabla utiliza algunos de los aspectos analizados de cada maestra, y. marcamos como infrecuente/a veces/frecuente su presencia en la práctica docente de cada una de ellas. Vale la pena aclarar que estas figuras no son una representación cuantitativa estricta, pues la valorización de la frecuencia de estos aspectos en la construcción de la actividad es el resultado de una apreciación subjetiva nuestra. Lo que buscamos ilustrar aquí es cómo las maestras inclinan por cierto tipo de acciones y planteamientos al diseñar y llevar acabo la actividad de aprendizaje y la evaluación, cómo entienden la participación de los estudiantes y el peso que dan a los lineamientos institucionales.

\begin{tabular}{|l|l|l|}
\hline Aspecto & Hilda & Lucía \\
\hline Tipográfico & & \\
\hline Grafocéntrico & & \\
\hline Didactica transmisiva & & \\
\hline Alumno Subordinado & & \\
\hline Institución curriculo & & \\
\hline Institución discursos & & \\
\hline Conocimiento Estable & & \\
\hline Digital & & \\
\hline Multimodal & & \\
\hline Didactica transformadora & & \\
\hline Aumnno participante & & \\
\hline Curriculo transformado & & \\
\hline Conocimiento Construible & & Frecuente \\
\hline Valores & A veces & \\
\hline
\end{tabular}

Fonte: La autora. 


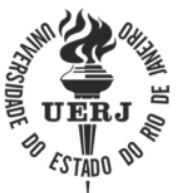

DOI: $10.12957 /$ teias.2021.62799

La segunda columna corresponde a la actividad con video realizada por Hilda. En ella se observa una tendencia de sostener prácticas centradas en la escritura y relaciones verticales con los alumnos, pues observamos en sus comentarios una deferencia por las formas y demandas institucionales. Ella comentó en una entrevista "hice un cuestionario sobre monografía... [vimos] cómo va la bibliografía, cómo hay que poner esta — las fichas bibliográficas —, las volví a retomar por título, por autor, por tema; hicieron unas en su cuaderno”. Aquí el uso de la primera persona es significativo, es ella quien hace un cuestionario y ella quien explica como se debe ordenar las fichas bibliográficas. Los alumnos hicieron unas fichas en su cuaderno de acuerdo con sus indicaciones. Este es un proceder común en el aula, pero también se podría transformar. Hilda organiza las actividades desde una lógica tipográfica, basada en lo impreso, aunque también tiene rasgos iniciales de elementos multimodales. Así mismo, la maestra da prioridad a los requerimientos institucionales y asume la mayor parte de la responsabilidad al llevar la actividad a la práctica. Aun así, a los alumnos les permite (es decir, ella autoriza) tomar algunas decisiones menores acerca de su trabajo. En su versión de la actividad, el conocimiento se concibe como algo estable y transmisible del profesor al estudiante.

La columna de Lucía, en cambio, ilustra una actividad diferente a la de Hilda aun cuando las dos trabajaron la realización de un video. En su actividad (siendo ella quien determina la utilización de la herramienta Movie Maker para el tema del reportaje), observamos que la didáctica tradicional y el papel subordinado de los alumnos tienen una presencia de baja intensidad. Justo cuando habla de la clase al revés, está buscando transformar la forma de relacionarse con los alumnos y la lógica de la actividad. En los otros aspectos, la profesora les otorga una fuerte responsabilidad a los estudiantes para realizar la actividad, dejándolos participar plenamente en las decisiones, revisiones y correcciones. Si bien el tema curricular es "el reportaje", los alumnos deciden su contenido y construyen los conceptos temáticos en el proceso de hacer el video y dialogar acerca del proceso. La maestra arranca el trabajo con los alumnos desde la actividad y no desde la definición de los conceptos.

La tabla muestra cómo las actividades son el resultado de una configuración de factores y que ninguno se puede entender en función de una sola característica. Cada maestra articuló diferentes acciones y creó un "racimo de prácticas" (SCHATZKI, 2010), de acuerdo con sus condiciones de trabajo, su adherencia a distintas tradiciones de enseñanza, su conocimiento disciplinar y sus arreglos materiales. En este sentido, los maestros pueden incorporar el uso de las tecnologías para "estructurar tareas, guiar la comprensión y apoyar los proyectos colaborativos de éstos" (UNESCO, 2008, p. 16), pero esto no necesariamente resultará en la transformación de la práctica o lograr "configurar un nuevo escenario en las relaciones entre los profesores, los alumnos y los contenidos de la enseñanza" como propuso Marchesi (2009) en la cita incluida al inicio de este artículo.

Esto nos permite concluir que la transformación de la práctica implica un largo camino de resignificación, cuestionamiento y reorganización de las actividades. También requiere replantear los contenidos, las formas de representación y la evaluación, articulado con la apropiación de nuevos recursos culturales, orientaciones didácticas y una nueva distribución de la responsabilidad. Para los alumnos de Hilda, la actividad consistió en reproducir definiciones, transformar un escrito de otra materia en video, seguir los requisitos formales de extensión y características dictadas por la maestra, así como presentar un examen en el cual puntualizaron por escrito los procedimientos y los pasos necesarios para producir un video. En cambio, los alumnos de Lucía tuvieron que asumir la responsabilidad de organizarse, tomar decisiones acerca de los contenidos y su representación, participar en discusiones conceptuales y sesiones de crítica constructiva para mejorar sus trabajos,

Revista Teias v. $22 \cdot$ n. $67 \bullet$ out./dez. $2021 \bullet$ 
construyeron definiciones propias a partir de la experiencia, discusión e investigación. En la medida en que se transforma la actividad, también varían los aprendizajes, es decir, lo que los alumnos de Lucía y los alumnos de Hilda aprendieron no fue lo mismo.

\section{APERTURA EN LUGAR DE CIERRE: EL RETO DE NUESTROS TIEMPOS}

Sin duda la pandemia que vivimos en este año establece un antes y un después en el uso de las tecnologías digitales para fines educativos. Sin embargo, los desafíos siguen siendo los mismos o cuando menos, muy parecidos. La crisis sanitaria puso en evidencia las desigualdades históricas de la región latinoamericana y exhibió la profunda disparidad en cuanto a las condiciones materiales y oportunidades de acceso a la educación. Trasladar las actividades y rutinas escolares a la casa mostró que las diferencias observables en la situación de los estudiantes incluyen no solamente el tipo de equipo y conectividad de sus casas sino también en la disposición de tiempos y espacios para el estudio, las posibilidades de ayuda, el acceso a recursos impresos y digitales, y las formas en que las familias vivieron y enfrentaron la pandemia.

También ha puesto en evidencia los limites de un currículo basado en disciplinas académicas cuando se están viviendo problemáticas inmediatas específicas que los alumnos y sus familias no pueden ignorar. En gran medida, la mudanza a medios como teleclases, tareas por internet, clases por video, conferencias colectivas (en los casos que esto sea factible) hizo que la escuela mostrara su verdadera cara, y cómo lo escolar implica administrar tareas y puntos más que educar.

Nos quedamos entonces con el reto de pensar en cómo transformar la escuela, las prácticas, lo que valuamos y validamos. Lo que la historia y análisis de Hilda y Lucía demuestran es que las tecnologías no hacen a la escuela y no transforman per se a la educación. Ofrecen nuevos entornos, materialidades y posibles usos, pero a través de la práctica éstos conviven y compiten con formas tradicionales. La transformación de la práctica docente demanda una revisión a fondo de lo que enseñamos, lo que validamos en la escuela, lo que premiamos en los alumnos. Implica también una revaloración del uso del tiempo, el proceso de la construcción de conocimientos y las formas de participación de los docentes y sus estudiantes. Esta problemática no es un producto de la pandemia, existía mucho antes en la modalidad presencial, sin embargo, ahora es ineludible. Covid-19 nos puso los límites de la educación y sus desigualdades a la vista de todos, ahora nos toca decidir qué vamos a hacer al respecto.

\section{REFERENCIAS}

BARTON, David; HAMILTON, Mary. Local literacies. Reading and writing in one community. Londres: Routledge, 1998.

BIGUM, Chris; DURRANT, Cal; GREEN, Bill; HONAN, Eileen; LANKSHEAR, Colin; MORGAN, Wendy, ... \& LEMKE, Jay. Digital Rhetorics: Literacies and Technologies in EducationCurrent Practices and Future Directions, 1997. (Volumes 1-3).

COOK-GUMPERZ, Jenny (ed.). The social construction of literacy. Cambridge: Cambridge University Press, 1986

COPE, Bill; KALANTZIS, Mary. Multiliteracies. Literacy learning and the design of social futures. Londres, Nueva York: Routledge / Taylor and Francis Group, 2000. 


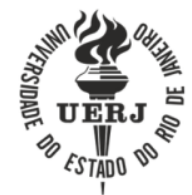

DOI: $10.12957 /$ teias.2021.62799

CUBAN, Larry. Oversold and underused: computers in the classroom. Cambridge: Harvard University Press, 2000.

DAVIDSON, Cathy. Now you see it. how the brain science of attention will transform the way we live, work and learn. Nueva York: Viking Press, 2011.

DREIER, Ole. Personal trajectories of participation across contexts of social practice. Outlines. Critical Practice Studies, 1 (1), 1999. p. 5-32.

GEERTZ, Clifford. Local knowledge. Nueva York: Basic Books, 1983.

GUERRERO, Irán. Ahi está el detalle: cambios minúsculos, rutas opacas y tecnologías míticas en la enseñanza de la Geografía en secundaria. México, Centro de Investigación y Estudios Avanzados del Instituto Politécnico Nacional, 2011.

HERNÁNDEZ, Gleider. Reading, writing and experience: literacy practices of young rural students. En KALMAN, Judith; STREET, Brian (eds.). Introduction, literacy and numeracy in Latin America. Local Perspectives and Beyond. Nueva York: Routledge, 2013. p. 1-15.

HERNÁNDEZ, Oscar; RENDÓN, Víctor; KALMAN, Judith (en preparación). Accompaniment: a sociocultural approach for rethinking practice and uses of digital technologies with teachers. En KNOBEL, Michele; KALMAN, Judith. Literacies, digital technologies and teachers professional development. NuevaYork: Peter Lang.

JARA-VALDIVIA, Ignacio. Las políticas de tecnología para escuelas en América Latina y el mundo: visiones y lecciones. Santiago de Chile: CEPAL. Recuperado de https://repositorio.cepal.org/handle/11362/4006. 2008.

KALMAN, Judith. El estudio de la comunidad como un espacio para leer y escribir. Revista Brasileira de Educação, n. 26, 2004. p. 5-28.

KALMAN, Judith; GUERRERO, Elsa. A social practice approach to understanding teachers learning to use technology and digital literacies in their classrooms. E-Learning and Digital Media, 10 (3), 2013. p. 260-275.

KALMAN, Judith; RENDÓN, Víctor. Use before know-how: teaching with technology in a Mexican public school. International Journal of Qualitative in Education. 27 (8). 2014. p. 974-991.

KRESS, Gunther. Literacy in the New Media Age. Londres-Nueva York: Routledge, 2003.

LANKSHEAR, Colin. The challenge of digital epistemologies. Education, Communication y Information. 3 (2). 2003. p. 167-183.

LANKSHEAR, Colin; KNOBEL, Michele. A new literacies sampler. Nueva York: Peter Lang Publishing, 2007.

LANKSHEAR, Colin; KNOBEL, Michele. New literacies. Nueva York: Peter Lang Publishing, 2011.

LAVE, Jean. Apprenticeship in critical ethnographic practices. Chicago: University of Chicago Press, 2011.

LAVE, Jean; WENGER, Etienne. Situated learning. Legitimate Peripheral Participation. Chicago: University of Chicago Press, 1991.

LEANDER, Kevin. You won't be needing your laptops today: wired bodies in the wireless classroom. p. 25-48. En LANKSHEAR, Colin; KNOBEL, Michele. (eds.). A new literacies sampler. Nueva YorkLondres: Peter Lang Publishing, 2007. 
LUKE, Carmen. Cyber-schooling and technological change: multiliteracies for new times. p. 67-88. En COPE, Bill; KALANTZIS, Mary (eds.). Multiliteracies. Literacy learning and the design of social futures. Londres-Nueva York: Routledge / Taylor and Francis Group, 2000.

MARCHESI, Álvaro. Preámbulo. p. 7-10. En CARNEIRO, Roberto; TOSCANO, Juan Carlos; DÍAZ, Tamara (eds.). Los desafíos de las TIC para el cambio educativo. Madrid: Fundación Santillana y OEI, 2009.

McFARLANE, Angela. El aprendizaje y tecnologias de la información. México: Biblioteca para la actualización del maestro, Secretaría de Educación Pública, 2001.

NELSON, Mark. Mode, meaning and synaesthesia in multimedia L2 writing. Language Learning $y$ Technology, 10 (2), 2006. p. 56-76.

NEW LONDON GROUP (NLG). A pedagogy of multiliteracies: designing social futures. Harvard Education Review, 1996.

ROGOFF, Barbara. Observing sociocultural activity on three planes: participatory appropriation, guided participation, and apprenticeship. En WERTSCH, James V.; DEL RÍO, Pablo; ALVAREZ, Amelia (eds.). Sociocultural Studies of Mind. p. 139-164. Cambridge: Cambridge University Press, 2008.

ROGOFF, Barbara; PARADISE, Ruth; MEJÍA ARAUZ, Rebeca; CORREA-CHÁVEZ, Maricela; ANGELILLO, Cathy. Firsthand Learning Through Intent Participation. Annu. Rev. Psychol. 54. 2003. p. 175-203. Recuperado de http://calteach.ucsc.edu/People/Instructors/documents/RogoffLearninginAdolescence.pdf.

ROGOFF, Barbara. Observing sociocultural activity on three planes: participatory appropriation, guided participation, and apprenticeship. Pedagogy and practice: culture and identities, 2008. p. 58-74.

SCHATZKI, Theodore. Materiality and social life. Nature and culture, 5 (2), 2010. p. 123-149.

SCRIBNER, Sylvia; COLE, Michael. The psychology of literacy. Cambridge: Harvard University Press, 1981.

SIMON, Roger. Teaching against the grain: texts for a pedagogy of possibility. Nueva York, WestportConneticut-Londres: Bergin and Garvey, 1992.

SUTHERLAND, Rosamund; ARMSTRONG, Victoria; BARNES, Sally; BRAWN, R.; BREEZEL, Nick; GALL, M.; METTHEWMAN, Sasha; OLIVERO, Federica; TAYLOR, A.; TRIGGS, Pat; WISHART, Jocelyn; JOHN, Peter. Transforming teaching and learning: embedding ICT into everyday classroom practices. Journal of Computer Assisted Learning. 20, 2004. p. 413-425.

SUTHERLAND, Rosamund; ROBERTSON, Susan; JOHN, Peter. Improving classroom learning with ICT. Londres: Routledge, 2009.

UNESCO. Estándares de competencias en TIC para docentes. París: Organizacioón de las Naciones Unidas para la Educación, la Ciencia y la Cultura, 2008. Recuperado de http://www.eduteka.org/EstandaresDocentesUnesco.php .

WARSCHAUER, Mark. Reconceptualizing the digital divide. First Monday. A peer reviewed journal on the Internet, 7 (7). 2002. Recuperado de http://ojphi.org/ojs/index.php/fm/article/view/967/888. 
DOI: $10.12957 /$ teias.2021.62799

Submetido em agosto de 2021 Aprovado em setembro de 2021

\section{Informações da autora}

Judith Kalman

Departamento de Investigaciones Educativas / Centro de Investigación y de Estudios Avanzados del Instituto Politécnico Nacional / México

E-mail:judymx@gmail.com

ORCID:

Link Lattes: http://lattes.cnpq.br/6539261716648088 